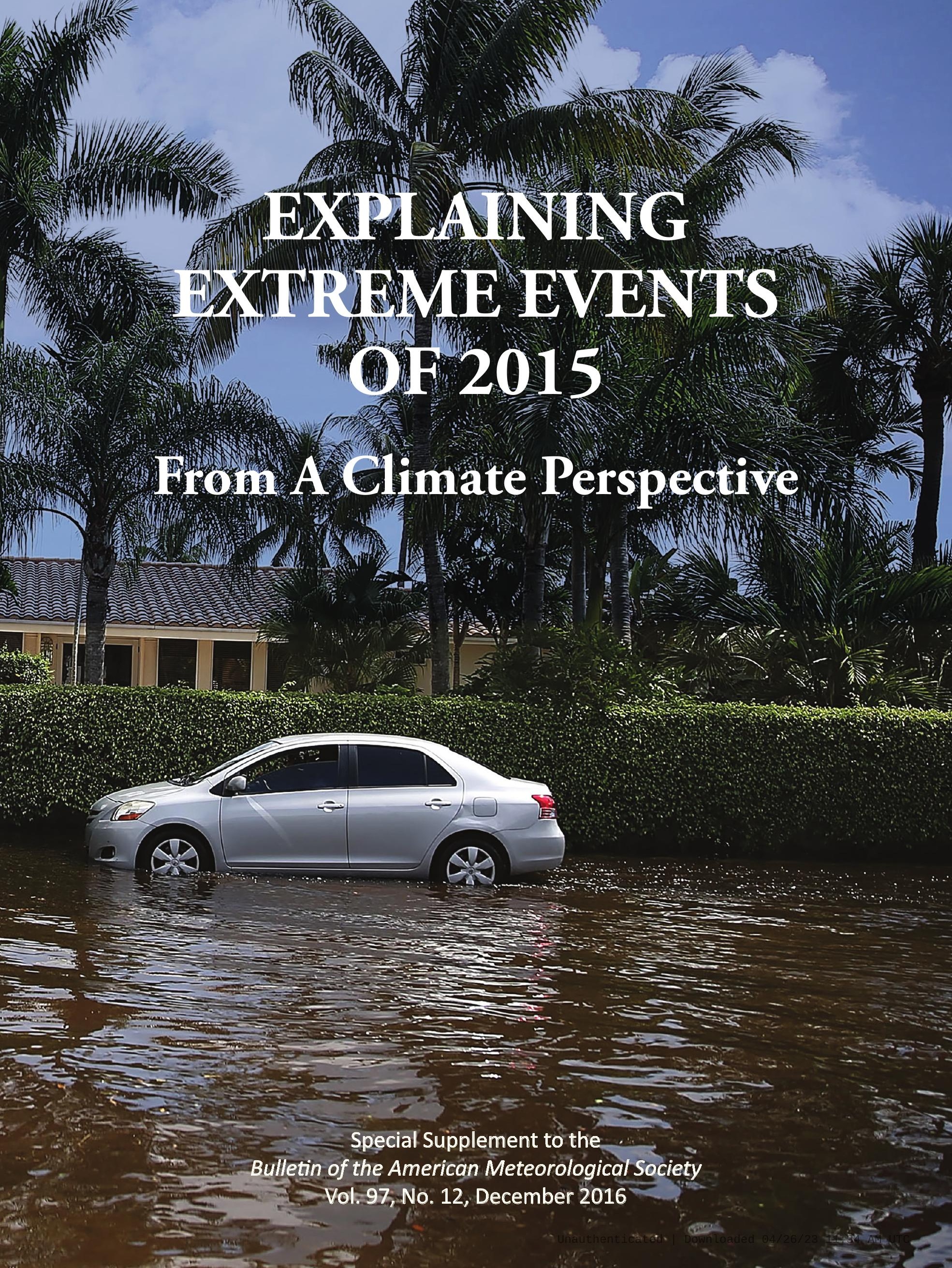




\section{EXPLAINING EXTREME \\ EVENTS OF 20I5 FROM A \\ CLIMATE PERSPECTIVE}

\section{Editors}

Stephanie C. Herring, Andrew Hoell, Martin P. Hoerling, James P. Kossin,

Carl J. Schreck III, and Peter A. Stott

Special Supplement to the

Bulletin of the American Meteorological Society

Vol. 97, No. 12, December 2016

American Meteorological Society 


\section{CORRESPONDING EDITOR:}

Stephanie C. Herring, PhD

NOAA National Centers for Environmental Information

325 Broadway, E/CC23, Rm IB-I3I

Boulder, CO, 80305-3328

E-mail: stephanie.herring@noaa.gov

\section{Cover CRedit:}

CPhoto by Joe Raedle/Getty Images-A vehicle drives through flooded streets caused by a combination of the lunar orbit which caused seasonal high tides and what many believe is the rising sea levels due to climate change on September 30, 20I5, in Fort Lauderdale, Florida. South Florida is projected to continue to feel the effects of climate change, and many of the cities have begun programs such as installing pumps or building up sea walls to try and combat the rising oceans.

\section{HOW TO CITETHIS DOCUMENT}

Citing the complete report:

Herring, S. C., A. Hoell, M. P. Hoerling, J. P. Kossin, C. J. Schreck III, and P.A. Stott, Eds., 20I6: Explaining Extreme Events of 2015 from a Climate Perspective. Bull.Amer. Meteor. Soc., 97 (I 2), SI-SI 45.

Citing a section (example):

Partain, J. L., and Coauthors, 2016: An assessment of the role of anthropogenic climate change in the Alaska fire season of 2015 [in "Explaining Extremes of 2015 from a Climate Perspective"]. Bull. Amer. Meteor. Soc., 97 (I2), SI4-SI8, doi:I0.II75/BAMS-D-16-0149.

\section{EDITORIAL AND PRODUCTION TEAM}

Riddle, Deborah B., Lead Graphics Production, NOAA/NESDIS National Centers for Environmental Information,

Asheville, NC

Veasey, Sara W., Visual Communications Team Lead, NOAA/ NESDIS National Centers for Environmental Information, Asheville, NC

Love-Brotak, S. Elizabeth, Graphics Support, NOAA/NESDIS National Centers for Environmental Information,

Asheville, NC

Fulford, Jennifer, Editorial Support, Telesolv Consulting LLC, NOAA/NESDIS National Centers for Environmental Information, Asheville, NC

Griffin, Jessicca, Graphics Support, Cooperative Institute for Climate and Satellites-NC, North Carolina State University, Asheville, NC
Maycock, Tom, Editorial Support, Cooperative Institute for Climate and Satellites-NC, North Carolina State University, Asheville, NC

Misch, Deborah J., Graphics Support, Telesolv Consulting LLC, NOAA/NESDIS National Centers for Environmental Information, Asheville, NC

Osborne, Susan, Editorial Support, Telesolv Consulting LLC, NOAA/NESDIS National Centers for Environmental Information, Asheville, NC

Sprain, Mara, Editorial Support, LAC Group, NOAA/NESDIS National Centers for Environmental Information, Asheville, NC

Young, Teresa, Graphics Support, STG, Inc., NOAA/NESDIS National Centers for Environmental Information, Asheville, NC 


\section{TABLE OF CONTENTS}

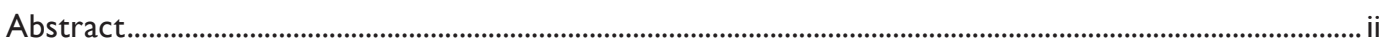

I. Introduction to Explaining Extreme Events of 2015 from a Climate Perspective.................................

2. Multimodel Assessment of Anthropogenic Influence on Record Global and Regional Warmth

During 2015 .......................................................................................................................................

3. What History Tells Us About 2015 U.S. Daily Rainfall Extremes ......................................................

4. An Assessment of the Role of Anthropogenic Climate Change in the Alaska Fire Season

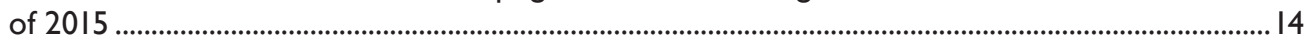

5. The 2014/15 Snowpack Drought in Washington State and its Climate Forcing ................................19

6. In Tide's Way: Southeast Florida's September 2015 Sunny-day Flood ................................................. 25

7. Extreme Eastern U.S. Winter of 2015 Not Symptomatic of Climate Change .....................................

8. The Role of Arctic Sea Ice and Sea Surface Temperatures on the Cold 2015 February

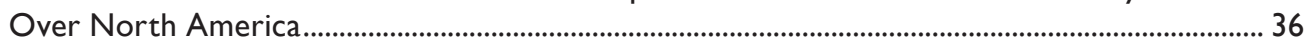

9. The 2015 Extreme Drought in Western Canada ................................................................................ 42

10. Human Contribution to the Record Sunshine of Winter 2014/15 in the United Kingdom .............47

II. The Role of Anthropogenic Warming in 2015 Central European Heat Waves ...................................5I

12. The 2015 European Heat Wave ....................................................................................................................

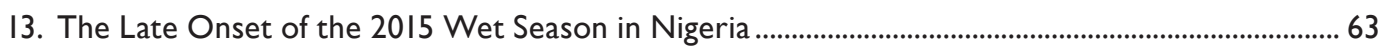

14. Human Influences on Heat-Related Health Indicators During the 2015 Egyptian Heat Wave .................................................................................................................................. 70

15. Assessing the Contributions of Local and East Pacific Warming to the 2015

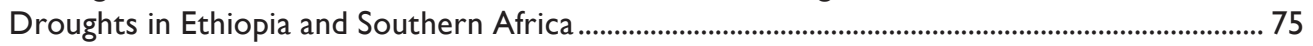

16. The Deadly Combination of Heat and Humidity in India and Pakistan in Summer 2015..................8I

17. The Heavy Precipitation Event of December 2015 in Chennai, India................................................... 87

18. Attribution of Extreme Rainfall in Southeast China During May 2015 ............................................. 92

19. Record-Breaking Heat in Northwest China in July 2015: Analysis of the Severity and Underlying Causes ......................................................................................................................... 97

20. Human Influence on the 2015 Extreme High Temperature Events in Western China................... 102

21. A Persistent Japanese Heat Wave in Early August 2015: Roles of Natural Variability and

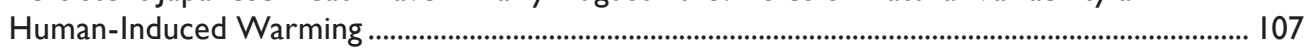

22. Climate Change and El Niño Increase Likelihood of Indonesian Heat and Drought........................ 113

23. Southern Australia's Warmest October on Record: The Role of ENSO and Climate Change....................................................................................................................................... 118

24. What Caused the Record-Breaking Heat Across Australia in October 2015? .............................. 122

25. The Roles of Climate Change and El Niño in the Record Low Rainfall in October 2015 in Tasmania, Australia.

26. Influences of Natural Variability and Anthropogenic Forcing on the Extreme 2015 Accumulated Cyclone Energy in the Western North Pacific

27. Record Low Northern Hemisphere Sea Ice Extent in March 2015 .............................................. 136

28. Summary and Broader Context.....................................................................................................141 
This fifth edition of explaining extreme events of the previous year (2015) from a climate perspective continues to provide evidence that climate change is altering some extreme event risk. Without exception, all the heat-related events studied in this year's report were found to have been made more intense or likely due to human-induced climate change, and this was discernible even for those events strongly influenced by the $2015 \mathrm{El}$ Niño. Furthermore, many papers in this year's report demonstrate that attribution science is capable of separating the effects of natural drivers including the strong 2015 El Niño from the influences of long-term human-induced climate change.

Other event types investigated include cold winters, tropical cyclone activity, extreme sunshine in the United Kingdom, tidal flooding, precipitation, drought, reduced snowpack in the U.S. mountain west, arctic sea ice extent, and wildfires in Alaska. Two studies investigated extreme cold waves and monthly-mean cold conditions over eastern North America during 2015, and find these not to have been symptomatic of human-induced climate change. Instead, they find the cold conditions were caused primarily by internally generated natural variability. One of these studies shows winters are becoming warmer, less variable, with no increase in daily temperature extremes over the eastern United States. Tropical cyclone activity was extreme in 2015 in the western North Pacific (WNP) as measured by accumulated cyclone energy (ACE). In this report, a study finds that human-caused climate change largely increased the odds of this extreme cyclone activity season. The 2015 Alaska fire season burned the second largest number of acres since records began in 1940. Investigators find that human-induced climate change has increased the likelihood of a fire season of this severity.

Confidence in results and ability to quickly do an attribution analysis depend on the "three pillars" of event attribution: the quality of the observational record, the ability of models to simulate the event, and our understanding of the physical processes that drive the event and how they are being impacted by climate change. A result that does not find a role for climate change may be because one or more of these three elements is insufficient to draw a clear conclusion. As these pillars are strengthened for different event types, confidence in the presence and absence of a climate change influence will increase.

This year researchers also link how changes in extreme event risk impact human health and discomfort during heat waves, specifically by looking at the role of climate change on the wet bulb globe temperature during a deadly heat wave in Egypt. This report reflects a growing interest within the attribution community to connect attribution science to societal impacts to inform risk management through "impact attribution." Many will watch with great interest as this area of research evolves in the coming years. 


\title{
16. THE DEADLY COMBINATION OF HEAT AND HUMIDITY IN INDIA AND PAKISTAN IN SUMMER 2015
}

\author{
Michael Wehner, Dáithí Stone, Hari Krishnan, Krishna AchutaRao, and Federico Castillo
}

We find that the deadly heat waves in India and Pakistan in 2015 were exacerbated by anthropogenic climate change. Although the impacts of both events were severe, the events themselves were not connected to each other.

Observations and Impacts. Andhra Pradesh, Telangana, and other southeastern Indian states suffered a deadly heat wave in late May and early June of 2015. Daily high temperatures exceeded $45^{\circ} \mathrm{C}$ in many places throughout India for several days in a row. In late June and early July, just a few weeks later, Pakistan also suffered from a deadly heat wave with similar daily high temperatures. Although the Pakistani heat wave occurred very soon after the Indian heat wave, they were distinct meteorological events. Ratnam et al. (2016) classify heat waves over India into two types, those that occur over north-central India and those that occur over coastal eastern India. The study finds that the former tend to be associated with anomalous blocking over the North Atlantic Ocean. Heat waves over coastal eastern India were found to be associated with westerly anomalies over the Indian landmass, thereby reducing the land-sea breeze along the coastal regions. Hence the Loo, a strong afternoon overland wind, brought hot and dry conditions to India (Fig. 16.1a). By late June, the Indian monsoon was well developed, curtailing these winds and terminating the heat wave (see www .tropmet.res.in/ lip/Publication/Scientific-Reports /RR-185.pdf). In Pakistan by this time, winds were onshore (Fig. 16.1b), and the unusually hot conditions were also unusually humid. The high numbers of deaths in both events are attributed not only to the weather conditions but also to institutional failures. Hospitals were overwhelmed with patients suffering from heat-related symptoms and at some point had to turn away patients (Salim et al. 2015). It is difficult to be precise about the ultimate number of fatalities

AFFILIATIONS: WeHNER, STONE, AND KRISHNAN-Lawrence Berkeley National Laboratory, Berkeley, California; ACHUTARAOIndian Institute of Technology Delhi, Hauz Khas, New Delhi, India; CASTILLO-University of California at Berkeley, Berkeley, California DOI:10.1175/BAMS-D-16-0145.I

A supplement to this article is available online $(10.1175$ /BAMS-D-16-0145.2) associated with these heat waves, but upwards of 2500 excess deaths are estimated to have occurred in the Indian heat wave (Ratnam et al. 2016) and at least 700 alone in the Pakistani megacity of Karachi (Masood et al. 2015) with many more throughout the country.

To further characterize these heat waves, we have analyzed 1973-2015 subdaily (hourly and 3-hourly) temperature and heat index (Steadman 1979a,b) calculated from the HadISD v1.0.4.2015p quality controlled weather station dataset (Dunn et al. 2012). Heat index, one of several methods to measure the combined effect of temperature and humidity on human health, is a bicubic function of both variables intended to fit a model of a fully clothed adult (see Supplemental Material for its definition). Figures $16.1 \mathrm{c}, \mathrm{d}$ show the daily maximum instantaneous heat index (thick red lines) and the temperature (thick black lines) associated with it during the heat waves in Hyderabad (in the Indian state of Telangana, WMO station number 431280) and Karachi (the largest city in Pakistan, WMO station number 417800). The pentadal averages of these daily maxima are shown with thin lines. Climatological averages over 1974-2014 are shown with horizontal dotted lines for May in Hyderabad and June in Karachi to show the events' relative severity. In Hyderabad, the daily maximum heat index was about $2^{\circ}-4^{\circ} \mathrm{C}$ higher than temperature during the heat wave. In Karachi, this difference was about $7^{\circ}-12^{\circ} \mathrm{C}$, reflecting a much higher relative humidity. The first column of Table 16.1 shows representative values of temperature and heat index during the most severe periods of the 2015 heat waves drawn from Figs. 16.1c,d.

Figures $16.2 \mathrm{a}, \mathrm{b}$ are scatterplots of relative humidity against temperature at the time of the daily maximum heat index value over the observational record of 1973-2015. Colored dots show the official U.S. NOAA advisory heat index levels of caution, extreme caution, danger, and extreme danger. In such hot climates, the 1974-2014 average daily maxi- 
(a)

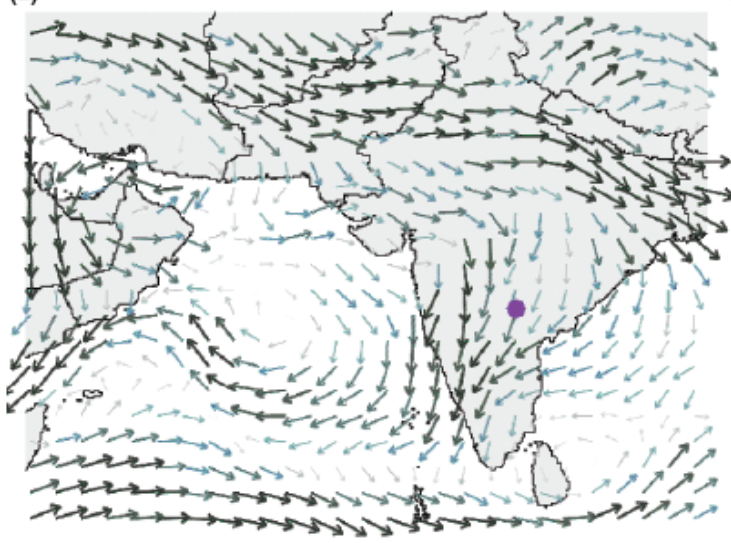

(c)

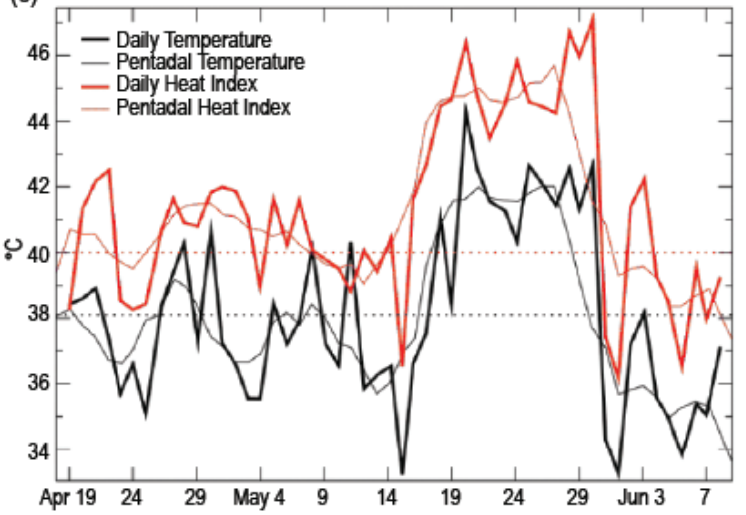

(b)

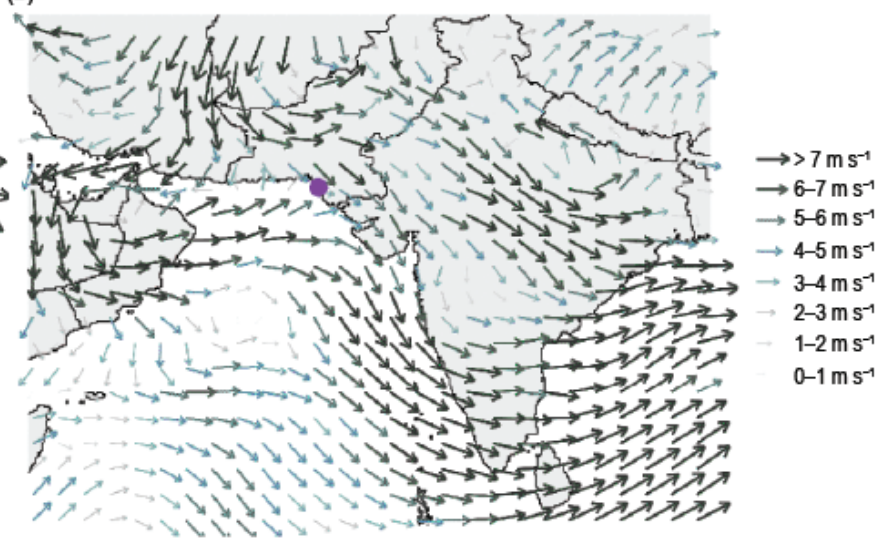

(d)

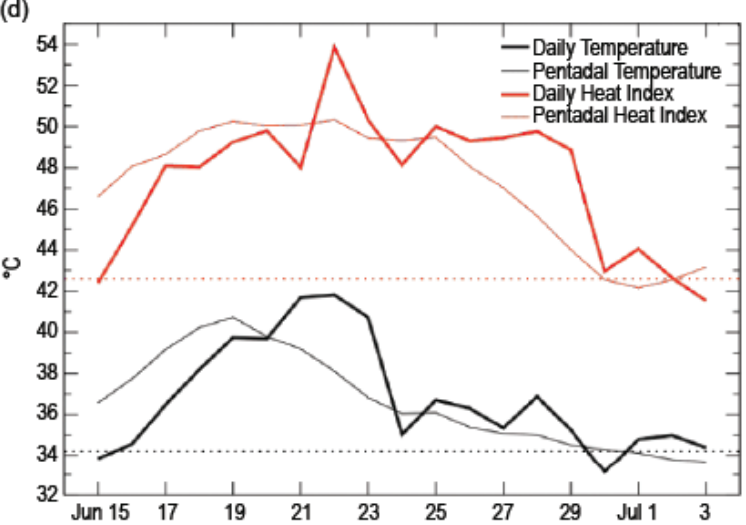

FIG.I6.I. (a),(b) Afternoon $700 \mathrm{hPa}$ wind vectors and speed from the ERA-Interim reanalysis on (a) 29 May 2015 (Indian heat wave) and (b) same on 30 Jun 2015 (Pakistani heat wave). The purple dots indicate the location of the weather stations used in this study. (c),(d) Daily maximum heat index values and associated temperatures during (c) the Indian heat wave and (d) same for the Pakistani heat wave. Dotted horizontal lines are I974-20 I4 climatological averages for the month of the occurrence of the peak in the heat waves.

mum heat index (indicated by the large black dot) is well within the advisory levels revealing that these U.S.-based statements were not developed for these regions. More widely applicable measures of the threat of severe heat wave to human health are not available (Wehner et al. 2016). Rare and dangerous events are along the upper-right edge of this two-dimensional distribution, which are not necessarily the highest temperatures. The 2015 heat waves are represented by asterisks. These figures reveal stark differences in both the heat waves and climatologies of the two cities. In Hyderabad, the 2015 heat wave was among the highest temperatures ever experienced but relative humidity was low, around 20\%. In Karachi, the 2015 heat wave was hot but not near record levels. However, because relative humidity was high $(35 \%-70 \%)$, the daily maximum heat indices were among the highest ever experienced. These combinations of temperature and relative humidity were rare events as is evident by the proximity of the asterisks to the edge of the distribution in Fig. 16.2b.
Analysis of possible human influence. The annual maxima of the pentadal average of the daily maximum heat indices and associated temperatures exhibit increasing trends for both stations (thin red lines in Supplemental Figs. S16.1a,b). To account for this, we use a nonstationary peaks over threshold extreme value methodology (Coles 2001) to fit a generalized Pareto distribution in order to estimate timedependent return periods for high daily and pentadal values. To incorporate the effect of anthropogenic climate change, we used a time varying estimate of $\mathrm{CO}_{2}$ (see www.esrl.noaa.gov/gmd/ccgg/trends/) as the covariate in the Pareto distribution using a 95th percentile threshold and a 3-week declustering. Using the event magnitudes in the first column of Table 16.1, we find a strong time dependence of the temperature and heat index return periods (Supplemental Figs. S16.1c,d) for the pentadal values. Very little time dependence in the return periods for the daily values for the Karachi station over the duration of the observational record is found, consistent with the 
Table 16.I. Estimates of observed daily maximum heat index and temperature $\left({ }^{\circ} \mathrm{C}\right)$, its return period (years), the corresponding quantile bias corrected return value in simulations of the actual world, and similar simulated quantities of a counterfactual world, human-induced risk ratio and return value changes. Bias corrections of the simulated actual distributions are made at the quantile corresponding to the observed return period. The magnitudes of the quantile bias corrections are the differences between values in the column labeled "Simulated Actual RV" and "Observed Value."

\begin{tabular}{|c|c|c|c|c|c|c|c|c|}
\hline & & $\begin{array}{c}\text { Observed } \\
\text { Value } \\
\left({ }^{\circ} \mathrm{C}\right)\end{array}$ & $\begin{array}{l}\text { Observed } \\
\text { RP } \\
\text { (years) }\end{array}$ & $\begin{array}{c}\text { Simulated } \\
\text { Actual } \\
\operatorname{RV}\left({ }^{\circ} \mathrm{C}\right)\end{array}$ & $\begin{array}{l}\text { Simulated } \\
\text { Counter- } \\
\text { factual } \\
\text { RP(years) }\end{array}$ & $\begin{array}{l}\text { Simulated } \\
\text { Counter- } \\
\text { factual } \\
\operatorname{RV}\left({ }^{\circ} \mathrm{C}\right)\end{array}$ & $\begin{array}{l}\text { Simulated } \\
\text { Risk Ratio }\end{array}$ & $\begin{array}{c}\text { Simulated } \\
\Delta \mathbf{R V}\end{array}$ \\
\hline \multicolumn{9}{|c|}{ Heat Index } \\
\hline Hyderabad & daily & 46.9 & 1.9 & 42.5 & 23.6 & 40.7 & 12.1 & 1.7 \\
\hline Hyderabad & pentad & 45.7 & 2.8 & 42.0 & 92.3 & 40.3 & 32.8 & 1.7 \\
\hline Karachi & daily & 53.5 & 4.0 & 49.3 & 31.1 & 46.9 & 7.7 & 2.4 \\
\hline Karachi & pentad & 50.4 & 43.9 & 49.1 & $>>1000$ & 46.6 & $>1000$ & 2.5 \\
\hline \multicolumn{9}{|c|}{ Temperature } \\
\hline Hyderabad & daily & 44.0 & 2.7 & 43.4 & 9.6 & 42.5 & 3.6 & 1.0 \\
\hline Hyderabad & pentad & 41.8 & 1.8 & 41.7 & 3.3 & 40.8 & 1.9 & 0.9 \\
\hline Karachi & daily & 41.9 & 2.1 & 43.0 & 2.7 & 42.5 & 1.3 & 0.5 \\
\hline Karachi & pentad & 40.7 & 5.9 & 42.8 & 9.4 & 42.3 & 1.6 & 0.5 \\
\hline
\end{tabular}

absence of a significant trend in the extrema of daily maxima for that station (thick lines in Supplemental Fig. S16.2b). Return periods of high temperature and head index in Hyderabad exhibit strong time dependence for both the daily and pentadal values, also consistent with relative magnitude of the trends and variations of Supplemental Fig. S16.1a. The 2015 values of return periods corresponding to estimated event magnitudes are shown in the second numeric column of Table 16.1. Because the $\mathrm{CO}_{2}$ covariate is clearly dependent on human activities, there is a statistically significant relationship between human influence and the heat index. However, because the statistical model does not consider that unforced natural variations may be coincidental with increases in atmospheric $\mathrm{CO}_{2}$, this statistical significance does not necessarily mean that an anthropogenic response has been detected by this analysis alone.

To more rigorously estimate a possible human influence, we utilize simulations drawn from the C20C+ Detection and Attribution Subproject (Folland et al. 2014). Temperature and relative humidity were extracted from the grid points nearest to the Hyderabad and Karachi airport weather stations from two 98-member ensemble simulations of the Community Atmospheric Model (CAM5.1) at a resolution of approximately $100 \mathrm{~km}$ (Risser et al. 2016, unpublished manuscript, available online at https:// arxiv.org/abs/1606.08908). Simulations from 1996-
2015 driven by observed sea surface temperatures and sea ice distributions represent the "world that was," referred to here as "actual." A counterfactual "world that might have been" set of simulations represents the climate system had humans not altered the composition of the atmosphere (Folland et al. 2014). In this case, an estimate of the human-induced changes to the sea surface temperature and sea ice distribution obtained from the CMIP5 models is removed from the lower boundary conditions and atmospheric trace gas and aerosol concentrations set to preindustrial values (Stone 2013). Comparison of model grid points to individual weather stations is performed with caution. Hyderabad Airport is located in the countryside well outside of the metropolitan area, and thus should be representative of temperature variations occurring on spatial scales resolved by the climate model. Karachi Airport is, however, located within the metropolitan area, and Karachi itself is a coastal city, so the climate model may not be properly resolving urban and coastal microclimate phenomena that are influencing weather at the airport. However, the pair of ensemble simulations use the same changes in land use and cover, so differences are predominantly a result of changes in atmospheric composition and ocean state rather than in the urban heat island. The model was determined to be fit for purpose by the tests outlined in Angélil et al. (2016a). Angélil et al. 2016b conclude that CAM5.1's estimates of the 
(a)

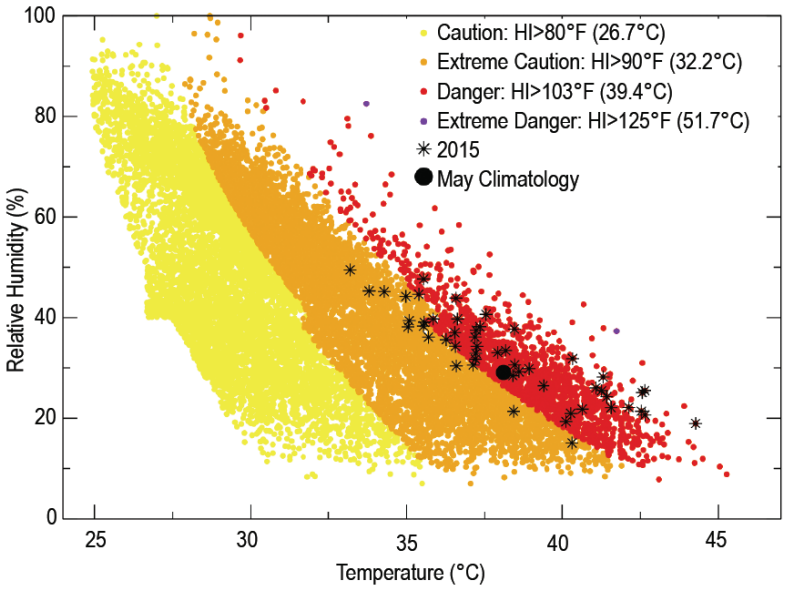

(c)

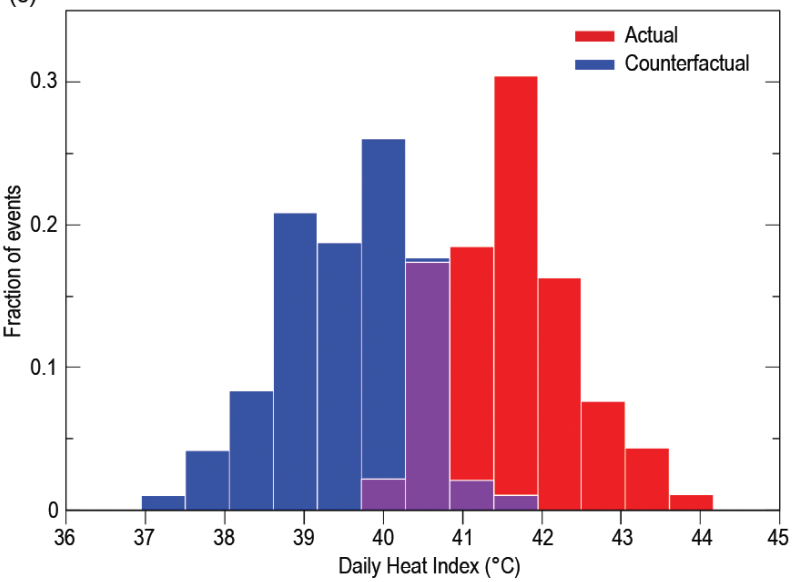

(b)

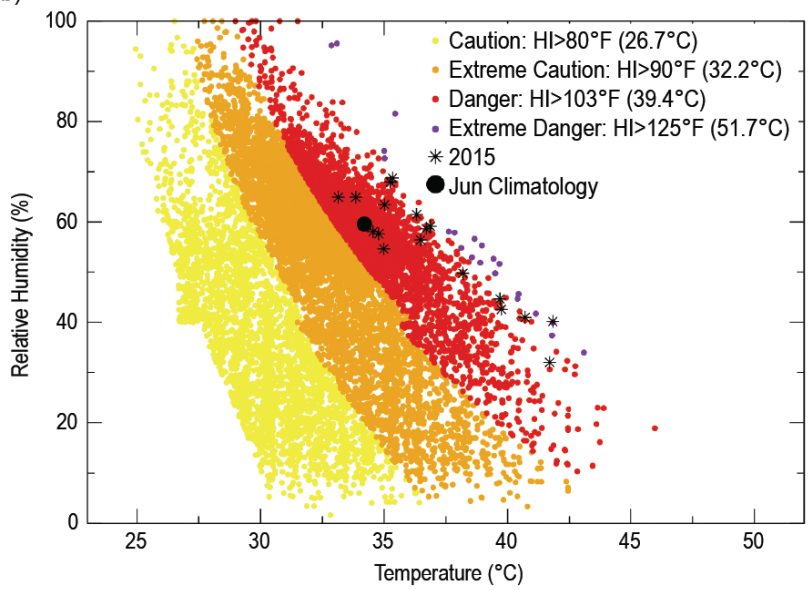

(d)

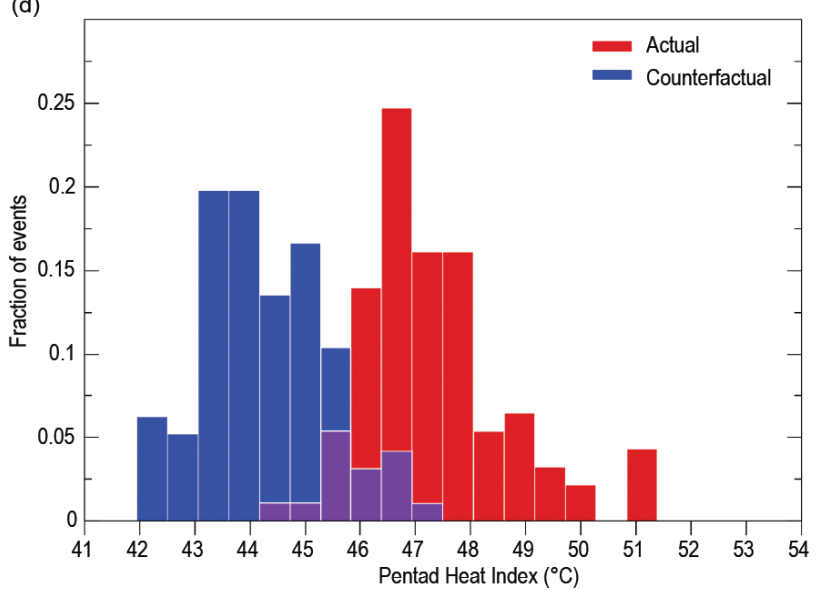

FIG. 16.2. (a),(b) Scatterplots of observed temperature and relative humidity from 1973-2015 at the time of the daily maximum heat index at (a) Hyderabad, India, and (b) Karachi, Pakistan. The 2015 heat wave days are shown by the asterisks. Other observations are colored according to NOAA heat index advisory levels. The large black dots are the May/Jun climatological averages. (c),(d) Histograms of uncorrected maximum pentadal average of daily maximum heat index for the counterfactual (blue) and actual (red) simulations, (c) May 2015, Hyderabad and (d) Jun 20I5, Karachi.

1-in-1-year and 1-in-10-year anomalous thresholds for hot days over India/Pakistan are all consistent with estimates from current reanalysis products. Figures 16.2c,d show histograms approximating the simulations' distribution of the pentadal average of the daily maximum heat index for the counterfactual world (blue) and actual world (red) during the month of the two heat waves' peak intensity and reveal a pronounced shift toward higher values caused by the changes in forcing due to anthropogenic activities. Corresponding histograms for the daily maximum heat index and for both measures of extreme temperature are shown in Supplemental Fig. S16.2. For both locations, the models' response in extreme temperature is less than in heat index but the profound difference in the daily and pentadal Karachi observational extremes revealed by changes in return period (Supplemental Figs. S16.1c,d) are not readily apparent in the simulations.

Utilizing the quantile bias correction method of Jeon et al. (2015), we estimate the changes in return period for corrected daily and pentadal values of peak temperature and heat index for both heat waves. This is used to define the "risk ratio," the ratio of the probabilities of reaching the corrected model estimates of the observed event in the factual and counterfactual simulations or, more simply, the inverse of the ratio of the corresponding return periods. Shown in Table 16.1, we find a substantial human increase in the risk ratio of heat index for both the Indian and Pakistani heat waves. The heat index risk ratio is substantially larger for pentadal values than it is for daily values. This is particularly relevant to assessing human-induced changes in the heat wave-related risk 
to human health and mortality, as is it is the longterm exposure to high heat that is most dangerous. Changes in simulated return values corresponding to the estimated observed return time are also shown in the last column of Table 16.1, revealing large humaninduced changes in the magnitude of heat waves of a fixed rarity for both cities.

We note that the climate model simulation (not shown) does not exhibit as large a trend in the estimated return periods of temperature and heat index as some of the HadISD observational products. However, the sampling uncertainty of the observations, represented by the error bars in Supplemental Figs. S16.1c,d, is large and the model is not necessarily inconsistent with the observations in this regard. Sampling uncertainty is much lower in the model because of the size of the ensemble dampens the inherent natural variability. In the simulations, the human signal is larger for the heat index than for temperature over both the daily and pentadal extremal measures at both locations (Table 16.1). We also find that for heat index, the human influence is greater on the pentadal scales than on the daily scales but that it is about the same for temperature at both locations. The time dependence of the Karachi observations could also be described this way, although there is essentially no trend in the daily extrema (Supplemental Figs. S16.1b,d). The time dependence of the Hyderabad observations is also similar except for the large change in the daily temperature (Supplemental Figs. S16.1a,c).

Jeon et al. (2015) demonstrated that risk ratio estimates for heat waves could be relatively insensitive to uncertainty in observed event magnitude. Hence, the principal uncertainties in the estimates of risk ratio and return value changes for heat wave occurrence in Table 16.1 stem from the use of a single climate model as well as the single estimate of counterfactual ocean state rather than observational uncertainty.

Conclusion. The deadly heat waves of 2015 in India and Pakistan were distinct meteorological events without obvious connection despite the proximity in location and time. We find a substantial human-induced increase ( $800 \%$ to $>100000 \%)$ in the likelihood of the observed heat indices. Alternatively, we also find a human-induced increase $\left(\sim 2^{\circ} \mathrm{C}\right)$ in the heat indices of nonindustrial events of equivalent rarity to that estimated in 2015 (Table 16.1). This anthropogenic influence is found to be higher for pentadal than for daily measures of heat wave severity, with potential implications for human health and mortality because of their dependence on heat wave duration.
ACKNOWLEDGEMENT. Wehner's and Stone's contributions to this work are supported by the Regional and Global Climate Modeling Program of the Office of Biological and Environmental Research in the Department of Energy Office of Science under contract number DE-AC02-05CH11231. Castillo's contribution is supported by the National Science Foundation grant No. 000237060 under the Earth System Model (EaSM2) program.

This document was prepared as an account of work sponsored by the U.S. government. While this document is believed to contain correct information, neither the U.S. government nor any agency thereof, nor the regents of the University of California, nor any of their employees, makes any warranty, express or implied, or assumes any legal responsibility for the accuracy, completeness, or usefulness of any information, apparatus, product, or process disclosed, or represents that its use would not infringe privately owned rights. Reference herein to any specific commercial product, process, or service by its trade name, trademark, manufacturer, or otherwise, does not necessarily constitute or imply its endorsement, recommendation, or favoring by the U.S. government or any agency thereof, or the regents of the University of California. The views and opinions of authors expressed herein do not necessarily state or reflect those of the U.S. government or any agency thereof or the regents of the University of California.

\section{REFERENCES}

Angélil, O., and Coauthors, 2016a: Comparing regional precipitation and temperature extremes in climate model and reanalysis products. Wea. Climate Extremes, 13, 35-42, doi:10.1016/j.wace.2016.07.001.

- D. Stone, M. Wehner, C. J. Paciorek, H. Krishnan, and W. Collins, 2016b: An independent assessment of anthropogenic attribution statements for recent extreme weather events. J. Climate, in press, doi:10.1175/JCLI-D-16-0077.1.

Coles, S., 2001: An Introduction to Statistical Modeling of Extreme Values. Springer Verlag, 208 pp.

Dunn, R. J. H., K. M. Willett, P. W. Thorne, E. V. Woolley, I. Durre, A. Dai, D. E. Parker, R. S. Vose, 2012: HadiSD: A quality controlled global synoptic report database for selected variables at long-term stations from 1973-2011. Climate Past, 8, 1649-1679, doi:10.5194/cp-8-1649-2012. 
Folland, C., D. Stone, C. Frederiksen, D. Karoly and J. Kinter, 2014: The International CLIVAR Climate of the 20th Century Plus (C20C+) Project: Report of the sixth workshop. CLIVAR Exchanges No. 65, 19, 57-59.

Jeon, S., C. J. Paciorek, and M. F. Wehner, 2016: Quantile-based bias correction and uncertainty quantification of extreme event attribution statements. Wea. Climate Extremes, 12, 24-32, doi:10.1016/j .wace.2016.02.001.

Masood, I., Z. Majid, S. Sohail, A. Zia, and S. Raza, 2015: The deadly heat wave of Pakistan, June 2015. Int. J. Occup. Environ. Med., 6, 247-248.

Ratnam, J. V., S. K. Behera, S. B. Ratna, M. Rajeevan, and T. Yamagata, 2016: Anatomy of Indian heat waves. Sci. Rep. 6, 24395, doi:10.1038/srep24395.

Salim, A., A. Ahmed, N. Ashraf, and M. Ashar, 2015: Deadly heat wave in Karachi, July 2015: Negligence or mismanagement? Int. J. Occup. Environ. Med., 6, 249.

Steadman, R. G., 1979a: The assessment of sultriness. Part I: A temperature-humidity index based on human physiology and clothing science. J. Appl. Meteor., 18, 861-873.

— $1979 \mathrm{~b}$ : The assessment of sultriness. Part II: Effects of wind, extra radiation and barometric pressure on apparent temperature. J. Appl. Meteor., 18, 874-885.

Stone, D., 2013: Boundary conditions for the C20C Detection and Attribution Project: The All-Hist/ est1 and Nat-Hist/CMIP5-est1 scenarios. Lawrence Berkeley National Laboratory, $18 \mathrm{pp}$. [Available online at http://portal.nersc.gov/c20c /input_data/C20C-DandA_dSSTs_All-Hist-est1 _Nat-Hist-CMIP5-est1.pdf.]

Wehner, M., F. Castillo, and D. Stone, 2016: Extreme heat waves, health, and welfare in a changing climate. Oxford Research Encyclopedia, Natural Hazard Science, in press, doi:10.1093 /acrefore/9780199389407.013.58. 


\section{Table 28.I. Summary of Results}

\section{ANTHROPOGENIC INFLUENCE ON EVENT}

\begin{tabular}{|c|c|c|c|}
\hline & INCREASE & DECREASE & NOT FOUND OR UNCERTAIN \\
\hline Heat & $\begin{array}{l}\text { Global Temperature (Ch. 2) } \\
\text { South India \& Sri Lanka (Ch. 2) } \\
\text { Central Europe (Ch. II) } \\
\text { Europe (Ch. I2) } \\
\text { Ethiopia and Southern Africa (Ch. I5) } \\
\text { N.W. China (Ch. I9) } \\
\text { W. China (Ch. 20) } \\
\text { Japan (Ch. 2I) } \\
\text { Indonesia (Ch. 22) } \\
\text { S. Australia (Ch. 23) } \\
\text { Australia (Ch. 24) }\end{array}$ & & Central Equitorial Pacific (Ch. 2) \\
\hline Cold & & Northeastern U.S. (Ch. 7) & $\begin{array}{l}\text { Mid-South Atlantic U.S. (Ch. 7) } \\
\text { N. America (Ch. 8) }\end{array}$ \\
\hline $\begin{array}{l}\text { Heat \& } \\
\text { Humidity }\end{array}$ & $\begin{array}{l}\text { Egypt (Ch. I4) } \\
\text { India \& Pakistan (Ch. 16) }\end{array}$ & & \\
\hline Dryness & $\begin{array}{l}\text { Indonesia (Ch. 22) } \\
\text { Tasmania (Ch. 25) }\end{array}$ & & \\
\hline $\begin{array}{l}\text { Heavy } \\
\text { Precipitation }\end{array}$ & China (Ch. I8) & & $\begin{array}{l}\text { Nigeria (Ch. I3) } \\
\text { India (Ch. I7) }\end{array}$ \\
\hline Sunshine & United Kingdom (Ch. I0) & & \\
\hline Drought & $\begin{array}{l}\text { Canada (Ch. 9) } \\
\text { Ethiopia and Southern Africa (Ch. I5) }\end{array}$ & & \\
\hline $\begin{array}{l}\text { Tropical } \\
\text { Cyclones }\end{array}$ & Western North Pacific (Ch. 26) & & \\
\hline Wildfires & Alaska (Ch. 4) & & \\
\hline $\begin{array}{l}\text { Sea Ice } \\
\text { Extent }\end{array}$ & & Arctic (Ch. 27) & \\
\hline $\begin{array}{l}\text { HIGH TIDE } \\
\text { FLOODS }\end{array}$ & SOUtheastern U.S. (CH. 6) & & \\
\hline $\begin{array}{l}\text { SNOWPACK } \\
\text { DROUGHT }\end{array}$ & WASHINGTON U.S. (CH. 5) & & \\
\hline TOTAL & 23 & 2 & 5 \\
\hline
\end{tabular}




\section{METHOD USED}

Heat

Ch. 2: CMIP5 modeling

Ch. II: Observations; weather@home modeling

Ch. 12: HadGEM3-A modeling

Ch. 15: CMIP5 modeling

Ch. 19: CMIP5 modeling with ROF; FAR

Ch. 20: CMIP5 modeling with ROF; FAR

Ch. 21: MIROC5-AGCM modeling

Ch. 22: Observations; CMIP5 modeling

Ch. 23: weather@home modeling; FAR

Ch. 24: BoM seasonal forecast attribution system and seasonal forecasts

Ch. 7: Observations; CMIP5 modeling

Ch. 8: AMIP (IFS model) modeling

Heat \&

Ch. 14: weather@home modeling

Humidity

Ch. 16: Non-stationary EV theory; C20C+ Attribution Subproject

Dryness

Ch. 22: Observations; CMIP5 modeling

Ch. 25: Observations; Modeling with CMIP5 and weather@home

Ch. 13: Observations; Modeling with CAM5.I and MIROC5

Heavy

Precipitation

Ch. 17: Observations; Modeling with weather@home, EC-Earth and CMIP5

Ch. 18: HadGEM3-A-N216 modeling; FAR

Sunshine

Ch. 10: Hadley Centre event attribution system built on the high-resolution version of HadGEM3-A

Ch. 9: Observations; CMIP5 modeling; Trend and FAR analyses

Drought

Ch. 15: CMIP5 modeling, land surface model simulations, and statistical analyses

Tropical

Cyclones

Ch. 26: GFDL FLOR modeling; FAR

Wildfires

Ch. 4: WRF-ARW optimized for Alaska with metric of fire risk (BUI) to calculate FAR

Sea Ice

Extent

HIGH TIDE

FLOODS

SNOWPACK

DROUGHT

Ch. 27: OGCM modeling

CH. 6: Tide-gauge data; Time-dependent EV statistical model

Ch. 5: Observations; CESMI modeling

\section{ACRONYMS:}

AMIP: Atmospheric Model Intercomparison Project

BoM: Bureau of Meteorology, Australia

BUI: Buildup Index

CAM: Community Atmosphere Model, http:www.cesm.ucar.edu

CESM: Community Earth System Model

CMIP: Coupled Model Intercomparison Project

FAR: Fraction of Attributable Risk

EC-EARTH: https://verc.enes.org/

EV: Extreme Value
GFDL FLOR: Geophysical Fluid Dynamics Laboratory Forecast version Low Ocean Resolution

GHCN: Global Historical Climatology Network

IFS: Integrated Forecast System

MIROC5-AGCM: Model for Interdisciplinary Research on ClimateAtmospheric General Circulation Model

OGCM: Ocean General Circulation Model

ROF: Regularized Optimal Fingerprinting

weather@home: http:www.climateprediction.net/weatherathome

WRF-ARW: Advanced Research (ARW) version of the Weather Research and Forecasting (WRF) model 